3. WeEks, We Bb. W.-Ocular headache. Bull. of the New York Acad. of Med., Vol. II, p. 487, 1935.

4. Penfield, Wilder.-Sensation: Its mechanisms and disturbances. Williams Wilkins, Baltimore, p. 399, 1935.

5. Marlow, F. W. - The relative position of rest of the eyes and the prolonged occlusion test. F. A. Davies and Co. 1924.

6. Hughes, Wendeli L.-Prolonged occlusion test. Arch. of Ophthal., Vol. II, p. 229, 1934

7. AMES, A. ET AL. - Size and shape of ocular images. Arch. of Ophthal., Vol. VII, p. 576, April, 1932. (Abstract in Brit.Ji. Ophthal., Vol. XVII, p. 105, 1933).

8. Aвraham, S. V.-Bell's phenomenon. Amer.Jl. Ophthal., Vol. XIV, p. 656 , 1931.

9. Williamson-Noble, F. A.-Functional disease of the eye. Trans. Ophthal. Soc. U.K., Vol. LIV, p. 381, 1934.

\title{
SPECIAL CASE OF MELANOSIS FUNDI : BILATERAL CONGENITAL GROUP PIGMENTATION OF THE CENTRAL AREA
}

\author{
BY
}

\section{Professor Arnold Loewenstein and Dr. Janet Steel}

(FROM THE TENNENT MEMORIAL INSTITUTE, UNIVERSITY OF GLASGOW, AND THE OPHTHALMIC INSTITUTION, GLASGOW)

Mauthner (1868) and Ed. v. Jaeger (1869), later on Frost, Stephenson, Dodd, Juler, Niels Hoeg (1911) described a rare (Leber) sharply characterised change of the fundus. It occurs in a sector of the fundus-very often a narrow one, but sometimes broader-covered with dark patches, round or irregularly-shaped, united in little groups. The size of the spot increases from the disc to the periphery. The area between the disc and fovea is always free. The spots lie underneath the vessels. In only two of all the cases published do the spots cover the retinal vessels, but these cases are not universally acknowledged. No retinal or choroidal change, and no functional defect have been observed.

As a sample of such a congenital anomaly-assumed to belong to the pigment epithelium, we take a picture of $\mathrm{H}$. Bedriska, a 26 years old girl. External examination normal; no defect; visual acuity $6 / 5$ in both eyes; +0.5 dptr. id. ; small pale pigment ring. In the macular area of the left eye there are very tiny colloid bodies, grouped pigment patches in a narrow sector downwards at 6 o'clock (Fig. 1), the smallest near the disc, the larger and darker ones more distant. In the more central part the greyish patches have a granulation feature, the peripheral ones being deep black and nearly twice the size of the disc. They are to be seen at the utmost periphery of the indirect image. No limit of the 
naevoid pigmentation is to be recognised in the periphery. The retinal vessels are in front of the pigment, and do not rise on crossing them. The largest peripheral patches have a thin pale frame. In the lower half of the right eye there is a bit of tabulation of the fundus. Iris blue-hair fair-no naevi of the skin. Function

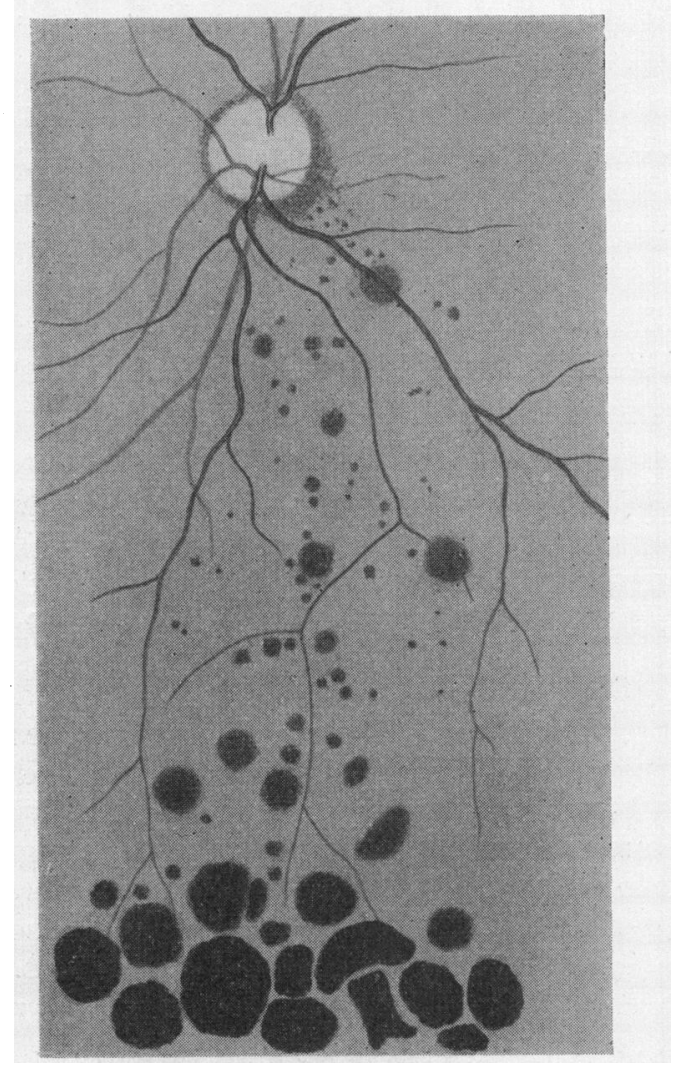

Fig. 1.

Typical grouped pigmentation (girl aged 26 years, left eye only).

normal-no field defect even for colours corresponding with the naevoid pigment.

The different names of this affection are: Grouped pigmentation of the retina (Niels Hoeg), melanosis retinae (Kraupa), naevoid pigmentation of the fundus (Leber). None of the authors found a change in the appearance during the time of observation. Most of the authors assume a seat of these pigmentations within the pigment epithelium-maybe a thickening into several rows or 
higher cells with more pigment. But so long as no case is examined anatomically, we are restricted to suppositions only. All the cases published so far (about forty) are very similar. All show one fact: The appearance of the central area is always free.

We were able to observe a case of a group pigmentation differing from all others published.

James C., aged 22 years. Fair hair; grey-brown irides; no abnormal pigmentation; healthy ; no family history ; mother's right eye highly myopic with staphyloma with no pigment anomaly. Vision : Right and left $=6 / 24$, with $-1.75 \mathrm{D} .=6 / 5$. Field normal; no central defect on the Bjerrum screen, not even relative for colours. Had never had any trouble with his eyes. Vision had been same all his life; does not wear glasses. No naevi, no melanosis of sclera, conjunctiva or cornea. W.R. negative.

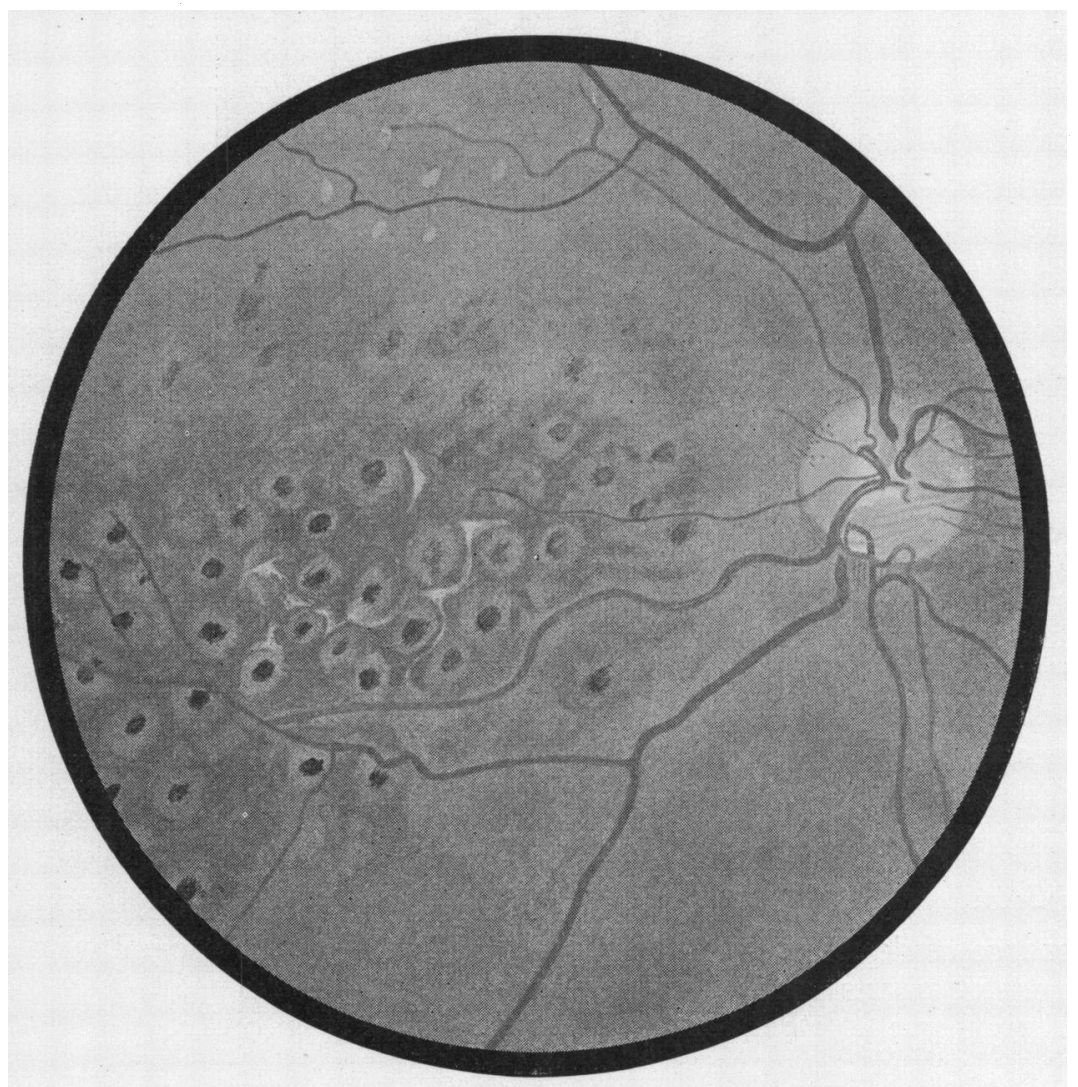

FIG. 2.

Bilateral groups pigmentation of the central area (man aged 22 years, symmetrical in both eyes). 
Both central areas between disc and fovea, and even temporal to the fovea are covered with patches of round shape (Fig. 2). Diameter of a circular spot is quarter of a disc, varying slightly in size; no very manifest prominence of vessels crossing over one of the patches; some slight bends over central patches. The colour of the patches is a dark grey in the central ones, greyish-black with indirect illumination, clearer and greyer with the direct convergent beam. The more peripheral ones are greyish white. The retinal reflexes are glittering over the central retinal area, granulated and intense between the different patches, but all the patches have focused in a certain position a clear red ring without any reflex. The breadth of the ring is about the same as the diameter

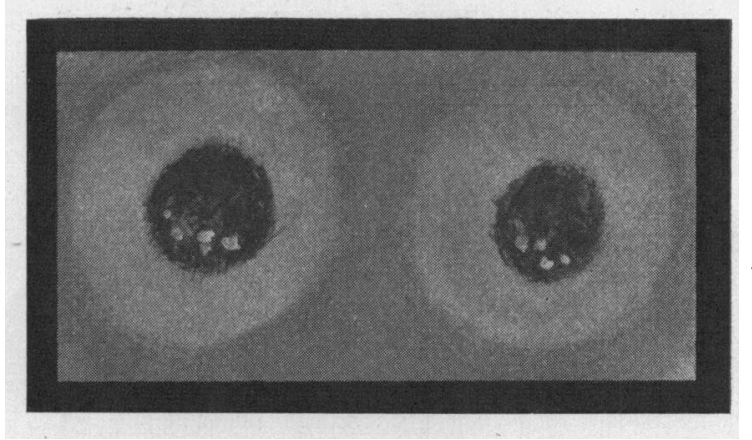

FIG. 3.

Halo and cysts.

of the patch. We could not find any difference in the refraction at the top of the patches and the base of the red ring. Some of the patches-more in the left eye than in the right-have a remarkable appearance-irregular, white spots of about one-sixth to oneeighth of the patch. Three of four of those whitish corpuscula are found in some of the patches (Fig. 3). With sodium light they appear as white-sometimes not-closed rings, sometimes as shining white small discs. The patches in the periphery above the temporal branch of the upper papillary vessels are clearer-a grey with more white in it.

Polarised ophthalmoscope. Gives no special change. The presence of double refracting substances could not be proved with the use of an analyser. (A. J. Ballantyne.)

Twin beam ophthalmoscope. No difference from ordinary polychrome ophthalmoscope.

Sodium Lamp. Spots are paler grey-white. Some new smaller grey spots appear, reaching more to the periphery above and below the central ảrea. 
Mercury Vapour Lamp. Deep reflexes between the pale patches, but the halo formation is reflex free.

The picture seems to be unknown. As the function is normal, no defect in the central field is detected, and no change in function observed by the intelligent man, we had to assume a congenital appearance. The extremely symmetrical shape, the regularity of the round patches, the absence of choroidal scars and functional diminution of the central area speak against the assumption of an intravitally acquired lesion.

There are very interesting details. The first is the difference in shade with direct and indirect light. If we assume, according to the schematic design (Fig. 4) a patchy thickness under the pigment epithelium, the latter seems to be a bit prominent, and will reflect the directly incident light intensely-greyish-but if the

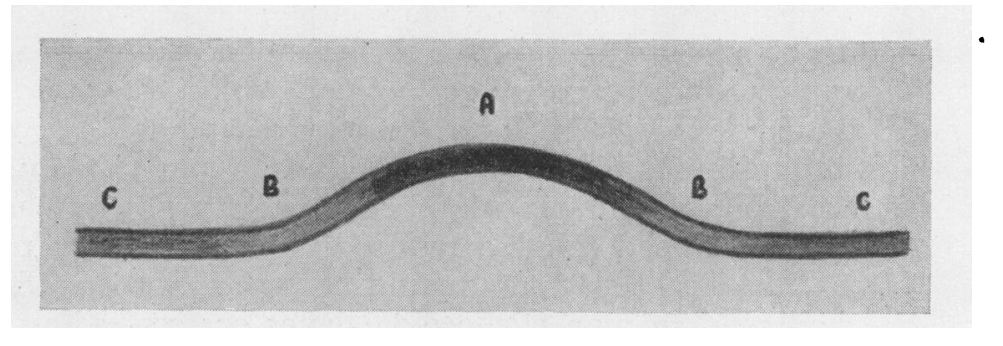

FIG. 4.

Schematic sketch.

light is reflected from a spot close to the patch by indirect illumination, we must expect a dark spot. The pigment in these central patches may be more densely distributed, while the patches in the more peripheral regions seem to contain less pigment.

A most remarkable appearance is the red ring found about the patches which is reflex free and most striking in the central area. It is to be understood as a slight notching of the reflecting surface, leading to the assumption that the retinal surface (membrana limitans interna) over the patch is slightly convex, while round about there is a ring where the retinal surface is concave (Fig. 4). A may reflect the light as a convex mirror, while $\mathrm{C}$ gives the granulated normal silvery light reflex of the dark macular area. The concave toric mirror of $\mathrm{B}$ reflects the light in another direction than that of $\mathrm{A}$ and $\mathrm{C}$. The normal central reflex appears between the patches, the slight convexity of the pigmented spot gives a very slight dark inconspicuous light reflex, while the haloes remain reflex free. Ballantyne's very valuable studies of the retinal reflexes (1940) taught us their careful observation. 
Without histological examination it is very difficult to find out the situation of the pigmented patches and the little cyst-like bodies, which are to be found easily with the convergent beam in some of the darker patches. We would locate them deep in the retina-perhaps in the pigment epithelium, or sub-epithelially, maybe belonging to the lamina vitrea chorioideae.

The explanation of the formal genesis of the first mentioned fundal naevoid pigmentation, of which about forty cases are mentioned in the literature has been impossible up to the present. Nobody could explain why in certain human beings such a wedgeformed pigmented group, of a special shape, is found. It seems even more difficult referring to our case.

The central part of the fundus as is well-known (Usher) is darker in an area of about 2 disc diameters than other parts. We know that with most higher mammals, especially the carnivorous ones, an intensely reflecting zone is present at the fundus - the tapetum cellulosum, consisting of flat endothelial-like cells of several rows under the pigment epithelium, within the choroid. It is an avascular layer just behind the chorio-capillaris.

We think it not impossible that we see in these grouped pigment spots in the central area an atavistic phenomenon, a patchy choroidal building of grouped cells-a reduced tapetum without production of the brilliantly shining guanin crystals. Sattler (1876) believed he had seen in man a choroidal layer corresponding to the tapetum, but Ida Mann stresses the fact that no trace can be found in man of the tapetum of carnivora. The idea that there are, here (and maybe in other congenital changes of the fundus), some atavistic remains of the tapetum, is worth studying. It is speculation only as long as we have no possibility of studying the anomaly anatomically.

It is easily understood that we are not entitled to call the whole appearance a " naevus" without proving the existence of naevus cells. One fact would remind us that the root of the whole appearance may be a naevus-that is the "cystic" change in some of the patches, well known in cases of conjunctival naevus. But that is, of course, not enough to fix the diagnosis. The conjunctival naevus cells are sub-epithelial, spherical groups separated from each other by fibrous tissue-not unlike the appearance of our ophthalmoscopic picture. The difference in size of the patches in the grouped pigmentation cases may depend on the structural difference of the choroidal tissue at the posterior pole and at the periphery.

We do not know if our case of bilateral group pigmentation of the central area is analogous to the previous cases of "grouped pigmentation," being different in many ways. 


\begin{tabular}{l|l}
\hline \multicolumn{1}{c|}{ Grouped pigmentation. } & \multicolumn{1}{c}{ Our Case. } \\
\hline One sector only. & Whole central area. \\
Different size of patches. & Patches almost of the same size. \\
One side. & Bilateral. \\
Central area always free. & Centrally located. \\
No "cystic" degeneration known. & "Cystic" changes. \\
No halo. & Haloes without reflex. \\
\hline
\end{tabular}

\section{Summary}

A case of typical grouped pigmentation of the fundus is described with its sector situation and different size of patches, increasing in size and intensity from the posterior pole to the periphery-one-sided. Secondly an unknown ophthalmoscopical picture of seemingly congenital pigment patches is described, located at the central area-symmetrical in both eyes, the patches being almost similar in shape and size and surrounded by a halo without reflex-dark by indirect illumination, greyish-white by direct illumnation. Some of the patches contain grey-white corpuscula-maybe cysts. The idea of an atavistic patch-like growth of Sattler's choroidal tapetum layer is mentioned, but it seems not impossible that the patches are provoked by naevus cell groups.

\section{REFERENCES}

Ballantyne (1940).-Proc. Roy. Soc. Med., Vol. XXXIV, p. 19.

KRAUPA (1917).-Arch. f. Augenheilk., Vol. LXII, p. 67.

LEBER (1916). -Graefe-Saemisch Handbuch, Vol. VII, II, X.A., p. 2042.

Niels Hoeg (1911).-Klin. Monatsbl. f. Augenheilk., Vol. XLIX, p. 1.

SaTtLeR (1876).-Arch.f. Ophthal., Vol. XXII, II, p. 1. 